\title{
FICÇÃO E HISTÓRIA NA REPÚBLICA DOMINICANA: TENSÕES DA DITADURA TRUJ ILLISTA NA LITERATURA CONTEMPORÂNEA
}

\author{
Adriana Aparecida de Figueiredo Fiuza
}

\begin{abstract}
RESUMO
$\mathrm{O}$ artigo examina sucintamente quatro obras consideradas fundamentais para a compreensão do romance do trujillato na América Hispânica, fenômeno literário que surge a partir da ocorrência histórica da ditadura de Rafael Leónidas Trujillo na República Dominicana. Estas narrativas têm como cerne a ficcionalização do período histórico em questão, revelando as mazelas impostas pela ditadura trujillista.
\end{abstract}

PALAVRAS-CHAVE: Literatura, História, Literatura Hispano-Americana, romance do trujillato.

$\mathrm{N}$ eil Larson (1988) denomina "novela del trujillato" ${ }^{1}$ a um conjunto de romances cuja temática se concentra em narrar o período da ditadura de Rafael Leónidas Trujillo, entre 1931 e 1961, na República Dominicana. Estas obras revelam os malefícios e o abuso de poder do ditador, combinando ficção e história. Trata-se de um fenômeno recorrente, sobretudo na literatura dominicana, constatado pelo elevado número de escritores contemporâneos que retomaram sucessivamente este tema da história recente do país em suas narrativas.

Fernando Valerio Holguín (2004), ao examinar a recente produção literária dominicana, apresenta uma explicação plausível para este fenômeno. Para o autor, "el trujillato [...] se ha convertido, para una gran parte de los dominicanos y dominicanas, en un trauma histórico a causa del terror, las torturas,

$\overline{1}$ LARSON, Neil. ¿Cómo narrar el trujillato? Revista Iberoamericana, N. 142 (1988): 89-98. 
los asesinatos y la represión generalizada de la población civil a manos del Servicio de Inteligencia Militar". ${ }^{2}$ Holguín defende que esse trauma ${ }^{3}$ histórico se reflete diretamente na narrativa dominicana, principalmente, a partir da segunda metade do século XX. Esse processo ocorre de duas formas, seja por meio de romances de ditador ou de narrativas que abordam diretamente o trujillismo.

O trauma histórico e social que se transfere para o discurso da literatura dominicana funciona como o trauma psicológico que vez ou outra retorna às memórias do indivíduo. Nestes termos, assim como o indivíduo, para libertar-se do problema, necessita reviver o episódio traumático para compreender seu mecanismo, a literatura, precisa recuperar o acontecimento traumático como forma de superação e sobrevivência social. Este processo parece estar presente não apenas na literatura dominicana, mas também em outros sistemas literários, cuja presença do ditador se configura no reflexo de uma sociedade enferma. As relaçóes de poder existentes nos regimes autoritários são a causa de desenvolvimento dos mais variados transtornos, como, por exemplo, o silêncio, decorrente do medo de expressar-se frente à censura e suas implicaçóes; como a prisão, a tortura e o desaparecimento; o inevitável apagamento da memória coletiva e individual e da história, que pode acarretar, entre outros problemas, perdas de identidade às futuras geraçóes.

A partir das concepçóes de Holguín, depreende-se que a literatura do trujillato poderia enquadrar-se também no que se define por romance de ditador ou romance da ditadura, narrativa cujo tema central é a figura do ditador e suas relaçóes sociais de poder. Não obstante, embora os termos romance de ditador e romance da ditadura sejam semelhantes, os mesmos possuem um

2 HOLGUÍN, Fernando Valerio. "En el tiempo de las mariposas de Julia Álvarez: Una reinterpretación de la historia." Latin Art Museum. <http://www.latinartmuseum.com/valerio_ holguin.htm "Monterroso y Cervantes: Intertextualidad y juego.” Centro Virtual Cervantes, 2004. http://cvc.cervantes.es/actcult/monterroso/acerca>. Acesso em: 18 mar. 2009.

3 É importante avaliar aqui o conceito de trauma, posto que o termo é utilizado para referir-se, de um modo geral, às expressóes da sociedade, como a história e a literatura, que se traduzem na constatação do horror presentes nos sistemas de governo autocráticos. Sendo assim, náo poderia ser diferente com a literatura que retoma as memórias da ditadura. Para a Psicologia, o conceito de trauma se refere ao transtorno psicológico em que ocorre no indivíduo um alto grau de ansiedade, hiper vigilância e condutas de fobias que evitam a possibilidade de lembranças do acontecimento traumático. 
matiz que os diferenciam. Segundo Castellanos e Martínez (1982) o romance de ditador, além de tematizar a ditadura, apresenta como personagem protagonista o próprio ditador, enquanto no romance da ditadura nem sempre a figura do tirano é a principal na narrativa. Além disso, o romance de ditador explora a complexa constituição da personalidade do tirano, o que não ocorre no romance da ditadura ${ }^{4}$.

O romance de ditador tem seu auge nas décadas de 1970 e 1980 nas literaturas hispânicas com a publicação de obras exemplares como Yo, el Supremo (1974) de Augusto Roa Bastos, El recurso del método (1974) de Alejo Carpentier e El otoño del patriarca (1975) de Gabriel García Márquez, embora não se trate de um acontecimento novo, posto que anteriormente já haviam sido publicadas nas letras hispânicas obras de mesma temática como Tirano Banderas (1926) de Ramón del Valle Inclán, El señor presidente (1946) de Miguel Ángel Asturias e El reino de este mundo (1949) também de Alejo Carpentier.

No romance de ditador os estereótipos que rondam o personagem são amplamente cultivados na tentativa de se explicar a constituição psicológica do tirano, portanto, algumas de suas características são abordadas; como sua velhice, quase de múmia; suas inumeráveis amantes; seu magnetismo pessoal, sua crueldade sem limite, seu machismo; sua relação terna de pai; seu amor pela figura materna; seu isolamento e sua solidão; entre outras.

Cabe observar que o escritor espanhol Ramón del Valle Inclán antecipa em muitos anos o gênero que seria uma marca das literaturas hispânicas, principalmente da literatura produzida na América. Além disso, ressalta-se que, embora outros autores tenham se preocupado com o tema e tivessem experiências semelhantes em seus países de origem, o ditador encarnado, totalmente fictício ou baseado em algum personagem histórico, é sempre proveniente de algum país hispano-americano.

Não obstante, muitos desses romances de ditador também se enquadram na categoria de romance histórico. Na realidade, de certa maneira todo romance poderia ser considerado histórico, assim como toda a ficção literária também, em um sentido mais amplo, se considerarmos que toda obra de arte é produto da historicidade de seu autor e da própria obra. Mas, ainda assim, não se pode

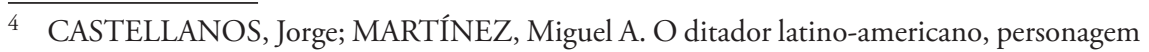
literário. Oitenta, vol. 6, 1982, p. 147-175. 
desconsiderar a teoria crítica da narrativa que evidencia no romance histórico a apropriação pelo discurso ficcional de um acontecimento ou de um personagem histórico que se converte em ficção, servindo, desta maneira, de material para a fabulação do romance. Esta é a definição de romance histórico que se propóe neste estudo, um pouco mais restrita, mas de igual consonância com autores como Seymour Menton (1993) $)^{5}$, Amalia Pulgarín $(1995)^{6}$, Antonio Roberto Esteves $(1995)^{7}$, Francisco García Orejas $(2003)^{8}$, Mercedes Juliá $(2006)^{9}$, entre outros. É importante verificar, conforme assevera Esteves (2007), que:

Independente do fato de se poder traçar uma genealogia para esse tipo de romance, buscando suas origens no romance histórico do século XIX, como fazem vários estudiosos, entre os quais, González Echevarría (1984), Raymond Souza (1988), Fernando Ainsa (1991, 1997 e 2003), Márquez Rodríguez (1991), Maarten Steenmeijer (1991), Seymour Menton (1993), Marilene Weinhardt (1994, 1998, 2000, 2004 e 2006), María Cristina Pons (1996), Peter Elmore (1997), André Trouche (1997, 2006), Celia Fernández Prieto (2003) ou Gloria da Cunha (2004), entre outros; ou de circunscrever o fenômeno diretamente na pós-modernidade, usando o conceito de metaficção historiográfica de Linda Hutcheon (1991), não se pode negar a importância dessa releitura da história proposta pelo romance. Da mesma forma, tem pouca relevância classificar esse tipo de narrativa em subcategorias como "romance histórico" simplesmente; "Novo romance histórico" (Ainsa, Menton); "narrativa de extração histórica" (Trouche); "narrativa históri-

5 MENTON, S. La nueva novela histórica de la América Latina, 1979-1992. México: FCE, 1993.

6 PULGARÍN, Amalia. Metaficción historiográfica. La novela histórica en la narrativa hispánica posmodernista. Madrid: Fundamentos, 1995.

7 ESTEVES, Antonio Roberto. O romance histórico brasileiro no final do século XX: quatro leituras. Letras de hoje. Porto Alegre, v. 42, n. 4, p. 114-136, dezembro de 2007.

8 GARCÍA OREJAS, Francisco. La metaficción en la novela española contemporánea. Madrid: Arco/Libros, 2003.

9 JULIÁ, Mercedes. Las ruinas del pasado: aproximaciones a la novela histórica posmoderna. Madrid: De la Torre, 2006. 
ca” (Cunha); "ficção histórica” (Weinhardt); ou repetir a feliz expressão de Hutcheon, "metaficçáo historiográfica" ${ }^{10}$.

Por fim, deve-se ainda enfatizar o caráter de crítica social presente nestas obras. Os romances do trujillismo ou do trujillato são obras que normalmente examinam a ditadura e seus efeitos prejudiciais na sociedade, denunciando as estruturas do poder estabelecidas pelo ditador e seus colaboradores. Ao analisar as relações entre literatura e poder, José Alcántara Almánzar ${ }^{11}$ expõe que a função crítica que os escritores promovem quando questionam o instituído é o motivo principal dos antagonismos entre o poder e os escritores.

Para Alcántara Almánzar, os escritores questionam em suas obras valores morais ultrapassados e práticas culturais obsoletas; além disso, possibilitam diferentes maneiras de captar a realidade, ao mesmo tempo em que criam novas formas de interpretar o mundo, o que significaria uma ameaça aos regimes antidemocráticos. Como afirma o ensaísta dominicano, "el lenguaje del escritor solo puede defender su derecho a crear con la palabra, su derecho a disentir y rebelarse contra las imposiciones irracionales y las deformaciones doctrinarias" 12

Segundo Ana Gallego Cuiñas (2005), apesar da existência de um número grande de romances que abordam o tema do trujillismo, no que se refere à crítica literária hispânica acerca deste fenômeno ${ }^{13}$, nota-se uma ausência de trabalhos que exploram a questão. No caso do contexto brasileiro, esta ausência poderia explicar-se por uma dificuldade ao acesso às letras e à história daquele país, diferentemente do que ocorre com livros publicados na Espanha e nos Estados Unidos, considerados centros editoriais, cuja produção cultural se distribui mais facilmente, inclusive por meio do recurso da internet.

Diante do exposto, o artigo examina algumas obras consideradas rele-

10 ESTEVES, Antonio Roberto. O romance histórico brasileiro no final do século XX: quatro leituras. Letras de hoje. Porto Alegre, v. 42, n. 4, p. 114-136, dezembro de 2007.

11 ALCÁNTARA ALMÁNZAR, José. Los escritores dominicanos y la cultura. Santo Domingo: Instituto Tecnológico de Santo Domingo, 1990, p. 183.

12 ALCÁNTARA ALMÁNZAR, José. Los escritores dominicanos y la cultura. Santo Domingo: Instituto Tecnológico de Santo Domingo, 1990, p. 184.

13 GALLEGO CUIÑAS, Ana. Trujillo: el fantasma y sus escritores. (análisis y sustematización de la novela del trujillato). Granada: Universidad de Granada, 2005. (Tese de Doutorado). 
vantes dentro da literatura do trujillato, no sentido de perceber as releituras que estas narrativas realizam da história, servindo de contraponto para observar as nuances do ditador ficcionalizado. Para tanto, escolhemos, cronologicamente, quatro romances sobre os quais discorreremos, são eles: Cementerios sin cruces (1949) ${ }^{14}$ do escritor dominicano Andrés Requena, La fiesta del Rey Acab (1959) ${ }^{15}$, do chileno Enrique Lafourcade, En el tiempo de las mariposas $(1994)^{16}$ da dominicana Julia Álvarez e La fiesta del chivo ${ }^{17}$ (2000) do peruano Mario Vargas Llosa.

Seguindo uma cronologia destas obras do trujillato, poderíamos referir-nos ao escritor dominicano Andrés Requena (1908-1952), que publicou Cementerios sin cruces em 1949, no México. A escolha da obra de Requena se justifica porque é o primeiro romance dominicano que trata da questão do trujillismo, em uma época nada cômoda para seu autor, visto que se vivia o auge da ditadura na República Dominicana. Neste romance, segundo José Alcántara Almánzar, o autor "ataca la dictadura acremente" e "Trujillo es espoleado con dureza" 18 .

Requena teve um destino parecido ao de outros exilados, sem proteção e com um destino incerto no exílio, foi perseguido pela ditadura e assassinado em uma rua de Nova Iorque no ano de 1952. De acordo com Alcántara Almánzar, em razão da publicação do romance, Trujillo mobilizou seus agentes secretos nos Estados Unidos até localizar e eliminar Requena, posto que suas narrativas denunciavam abertamente as perseguiçóes, os assassinatos e as torturas que sofriam os dominicanos ${ }^{19}$.

Cementerio sin cruces foi publicado com o subtítulo Novela del martirio de la República Dominicana bajo la rapaz tiranía de Trujillo, o que já demonstra o caráter de denúncia do romance. A dedicatória, "A los miles de dominicanos

14 REQUENA, Andrés. Camino de fuego y Cementerio sin cruces. Santo Domingo: Ferilibro, 2001.

15 LAFOURCADE, Enrique. La fiesta del rey Acab. Barcelona: Círculo de Lectores, 1974

16 ÁLVAREZ, Julia. En el tiempo de las mariposas. Madrid: Punto de Lectura, 2007.

17 VARGAS LLOSA, Mario. La fiesta del chivo. Madrid: Alfaguara, 2000.

18 ALCÁNTARA ALMÁNZAR, José. Los escritores dominicanos y la cultura. Santo Domingo: Instituto Tecnológico de Santo Domingo, 1990, p. 191.

19 ALCÁNTARA ALMÁNZAR, José. Narrativa y sociedad en Hispanoamérica. Santo Domingo: Instituto Tecnológico de Santo Domingo, 1984, p. 93. 
asesinados por Trujillo, y cuyas muertes tienen que ser cobradas" ${ }^{20}$ também não deixa de revelar a vertente ideológica de oposição ao trujillismo, presente na obra, e seu gesto reivindicativo. Alcántara Almánzar vê de forma negativa esta questão, ao afirmar que "las novelas de Requena caen en el terreno de lo panfletario, pues el carácter de protesta y denuncia supera con mucho los valores literarios de las mismas" ${ }^{21}$. Entretanto, esta análise poderia ser considerada uma visão simplista do romance de Requena, uma vez que a obra, em termos estéticos, não está em desvantagem em relação a obras de autores renomados, a exemplo de La fiesta del chivo de Mario Vargas Llosa, recontando uma vez mais a trágica história da República Dominicana.

Ainda sobre a questão do título, o mesmo se reporta ao fato de que na narrativa Trujillo não permitia que se pusessem cruzes nas sepulturas dos mortos, certamente uma maneira de amenizar a imagem de horror provocada pelo número descomunal de falecidos traduzido na imagem de milhares de cruzes. A trama se estrutura em dois momentos: em um deles é narrado o assassinato de Rafael Moreno, ocorrido por motivo de vingança política. No outro, é narrado o velório de Moreno e, consequentemente, o medo que se instaura nos presentes ao se comentar o sucedido com o morto.

Para solucionar tal impasse cria-se uma linguagem de silêncios, mediada pelo terror. Entretanto, apesar de a existência de um perigo iminente para os que se apresentassem no velório, por estar implícito que os mesmos estariam do lado do assassinado e, portanto, contra Trujillo, a população se revolta e comparece ao cortejo de Moreno, subvertendo o código do silêncio imposto nestas circunstâncias. Ao final, a polícia política de Trujillo intervém dissipando o cortejo considerado ilegal.

Outro tema que emerge neste episódio é o da delação, muito comum no âmbito das ditaduras e não apenas nas latino-americanas. Neste caso, o delator de Moreno havia sido Bolito Carías, vizinho da família Moreno, que sente um profundo remorso por ter sido indiretamente o culpado pelo assassinato ao revelar as açóes políticas do morto. A maneira que o personagem encontra para amenizar seu arrependimento é prover o velório para que náo

${ }^{20}$ REQUENA, Andrés. Caminos de fuego y Cementerio sin cruces. Santo Domingo: Ferilibro, 2001, p. 180.

21 ALCÁNTARA ALMÁNZAR, José. Narrativa y sociedad en Hispanoamérica. Santo Domingo: Instituto Tecnológico de Santo Domingo, 1984, p. 26. 
faltasse o que servir aos presentes. Nestes termos, afirma o narrador: "Bolito Carías proseguía en su empeño de que nada faltase para que fuera frecido a los visitantes." 22 . Embora o verdadeiro autor do crime houvesse sido o sargento Aceituna, Carías é quem comenta ao grupo do Exército de Trujillo as supostas atividades políticas de Rafael Moreno, considerado por todos um louco indefeso, alienado de sua condição política e social.

O outro momento da narrativa focaliza María del Carmen, filha de um jornalista preso, que tenta de todas as formas possíveis conseguir o indulto do pai. Ao saber das terríveis condiçóes das prisóes trujillistas, a personagem arrisca-se para salvá-lo. Como parece ser uma ocorrência nos romances do trujillato, María del Carmen, ao saber que é desejada sexualmente por Trujillo, pensa em entregar-se como oferenda ao ditador, a fim de alcançar o benefício em favor do pai.

Sobre a questão da representação simbólica da personagem, afirma Ana Gallego Cuińas: "ella es el símbolo de la vejación y humillación por la que pasan las mujeres del país, realidad que volverá a cobrar protagonismo en la novela del trujillato hasta los noventa" ${ }^{23}$. De fato, esta questão dos abusos sexuais do tirano é algo extremamente vexatório e que fere a dignidade feminina. Também é algo recorrente nos romances posteriores. $\mathrm{O}$ mesmo ocorre com a personagem Urania de La fiesta del Chivo, que é obrigada a entregar-se ao ditador como forma de agradar Trujillo em benefício de seu pai. Por outro lado, com Minerva de En el tiempo de las mariposas de Julia Álvarez ocorre o contrário, a personagem não aceita a abordagem do tirano em uma festa, o que se transforma em motivo pessoal para perseguir sua família.

Gallego Cuiñas enfatiza também que o romance de Requena é o primeiro que se ocupa da figura da primeira-dama, Doña María ${ }^{24}$. A personagem é retratada na trama como uma mulher forte, consciente de seu papel de esposa

22 REQUENA, Andrés. Caminos de fuego y Cementerio sin cruces. Santo Domingo: Ferilibro, 2001, p. 187.

23 GALLEGO CUIÑAS, Ana. Trujillo: el fantasma y sus escritores. (análisis y sustematización de la novela del trujillato). Granada: Universidad de Granada, 2005. (Tese de Doutorado), p. 176.

24 GALLEGO CUIÑAS, Ana. Trujillo: el fantasma y sus escritores. (análisis y sustematización de la novela del trujillato). Granada: Universidad de Granada, 2005. (Tese de Doutorado), p. 170. 
de Trujillo e, portanto, do poder que sua posição social lhe investe. Em virtude disso, ela também mandava assassinar àqueles que ela considerava seus inimigos, principalmente as mulheres pelas quais o marido se interessava e que poderiam concorrer em pé de igualdade, disputando o status de primeira-dama. Ao mesmo tempo, é a personagem da narrativa que se reveste de coragem para enfrentar o ditador, em muitas passagens insultando-o arduamente, inclusive diante de seus correligionários. Nestes termos afirma a personagem:

- Chapita está ahí, ?verdad, Larguito?

- Sí, señora.

El dictador los miró con visible turbación, porque cuando su mujer le llamaba públicamente con aquel apodo tan odiado por él, significaba que venía presa de la más grande cantidad de cólera que su cuerpo pequeño y barrigón podía soportar. Entonces era mejor que él se quedara solo, y ordenó al grupo que esperara en un adjunto salón. ${ }^{25}$

A passagem relata a chegada da primeira-dama a uma reuniáo de Trujillo com seus subalternos. Doña María interrompe o compromisso para chamar a atenção do ditador para seus problemas pessoais, dirigindo-se a ele pelo odiado apelido de "Chapita", uma referência paródica às medalhas que o tirano levava na farda militar, símbolo de sua suposta distinção como governante. Para evitar mais constrangimentos, Trujillo dispensa o grupo para que este não presencie a humilhação que sua mulher invariavelmente lhe imputava nestes momentos. O fragmento é relevante para visualizarmos a força de Doña María ao enfrentar o tirano. Desta maneira, ela pode ser considerada o correlato feminino do tirano ${ }^{26}$. O discurso é paródico e carnavalizado, uma vez que há a presença do cômico na obra como forma de subverter a ordem da ditadura.

Outro romance importante que trata do tema é La fiesta del rey Acab de Enrique Lafourcade (1927), publicado em 1959. A obra narra o desapa-

25 REQUENA, Andrés. Caminos de fuego y Cementerio sin cruces. Santo Domingo: Ferilibro, 2001, p. 215.

26 GALLEGO CUIÑAS, Ana. Trujillo: el fantasma y sus escritores. (análisis y sustematización de la novela del trujillato). Granada: Universidad de Granada, 2005. (Tese de Doutorado), p. 170. 
recimento, sequestro e assassinato do professor basco, exilado na República Dominicana, Jesús de Galíndez. Refere-se satiricamente ao ditador César Alejandro Carrillo Acab da República Dominicana e ao episódio de horror representado pelo assassinato violento do basco Jesús. Apesar de Lafoucarde colocar uma nota introdutória em que afirma que se trata puramente de ficção, obviamente o ditador César Carrillo é uma alusão a Rafael Leónidas Trujillo, assim como o basco Jesús refere-se evidentemente a Jesús de Galíndez e Jessie, esposa de Carrillo, é o correlato da primeira-dama Doña María.

La fiesta del Rey Acab relata três histórias simultâneas: a do planejamento e execução do assassinato do ditador no dia da festa de seu sexagésimo terceiro aniversário; a da própria celebração de Carrillo e, um pouco menos central, o sequestro, a prisão e o assassinato de Jesús, incinerado vivo na caldeira de um navio no dia da celebraçáo do ditador. O plano narrativo dos conjurados revela como a oposição, formada basicamente por estudantes, militares e partidos políticos, trabalha silenciosamente para a derrubada do governo de Carrillo, até a concatenação de um plano para a execução do tirano, única alternativa encontrada para a deflagração da democracia no país.

O foco narrativo do ditador e seus cúmplices é construído de forma a mostrar uma degradação de valores éticos e morais, em que não há regras sociais para os que representam o poder. Assim, todos os personagens envolvidos com o poder do ditador atuam de maneira a corroborar as atitudes megalomaníacas do tirano. A corrupção, a violência e a criminalidade estão presentes nas esferas sociais que representam o poder, como Carrillo e sua corte de bajuladores, os altos comandos do Exército, os diplomatas estrangeiros, os políticos norte-americanos beneficiados financeiramente, etc.

O retrato que se faz do tirano é o de um homem à beira da loucura, perdido entre o passado e o presente, entre a juventude e a senilidade, a qual não aceita. Esta dicotomia gera conflitos pessoais, medos e vilezas que se refletem em atitudes desequilibradas, em assassinatos criminosos como o de Jesús. $\mathrm{O}$ medo de ser morto, de ser substituído por outro, parece apoderar-se de Carrillo, manifestando-se em crises de pânico, que o levam a encerrar-se em seu quarto com um temor descontrolado. Este quadro doentio agrava-se à medida que a narrativa precipita-se para o final. De forma hiperbólica, o narrador termina por descrever um personagem animalesco, um homem sem moral que transforma a República Dominicana em seu feudo particular. 
Além dessa questão, o romance toca em outra característica deste tipo de narrativa: o tema da perpétua solidão ocasionada pela posição do ditador, que se encontra preso em seu "labirinto de solidão", habitado pelo medo da traição e pelo egoísmo. Neste contexto, Carrillo é o ser mais solitário do enredo, o personagem que vive à espera de uma traiçáo que o aniquile e o destitua do poder. Seu único amigo e confidente é o filho Carlitos, uma criança de nove anos, a quem segreda suas angústias, aborrecimentos e pede conselhos para resolver os problemas. $\mathrm{O}$ menino, em seu universo infantil, parece ser o único personagem ponderado no romance.

Jessie é a esposa de Carrillo, quem a insulta de várias formas, pela existência de seus amantes e por sua conduta desmoralizante, inclusive por seu conhecimento acerca de fraudes e abusos políticos no governo. Entretanto, ela não se cala diante das injúrias do tirano e, assim como a personagem de Dońa María do romance Cementerio sin cruces, resiste ao tirano violentamente. Jessie se dirige ao tirano chamando-o Acab, uma referência ao rei de Israel, mencionado no Livro dos Reis da Bíblia, o que lhe causava um grande mal estar. Segundo o Diccionario Enciclopédico Hispanoamericano, Acab era

El más impío de los reyes de Israel. Casó con Jezabel, hija del rey de los sidonios, mujer altiva, cruel y digna de tal esposo, y a sus instancias levantó un altar a Baal, ídolo de Sidón. Acab murió en una batalla contra el rey de Siria, y la sangre que salió de sus heridas fue lamida por los perros en el mismo lugar en que había bebido la de Naboth, muerto por orden de Jezabel por no haber querido venderle una viña para ensanchar el palacio real (898 antes de J. C.). Su reinado duró veintidós años. ${ }^{27}$

Esta representação bíblica de Acab se assemelha ao que o narrador perfila acerca de Carrillo no romance. Assim sendo é interessante observar que, da mesma maneira como o governo do ditador inicia, ele também finaliza. Trata-se de uma alusão ao conflito entre Acab e Naboth, cujos sangues haviam sido bebidos por cães. Noboth morre por uma vingança personificada

27 DICCIONARIO enciclopédico hispanoamericano de literatura, ciencias y artes, 2007, p. 191. Disponível em: < http://www.filosofia.org/enc/eha/eha.htm>. Acesso em: 15 mai 2009. 
por Acab e este também é abatido no mesmo local que Noboth, em uma batalha. Neste sentido, para tomar o poder, Carrillo deflagra uma bomba; da mesma maneira, para tomá-lo de suas mãos, os conjurados depositam outro explosivo, camuflado em um arranjo de lírios. Por fim, pode-se afirmar que Carrillo é a metáfora do poder absoluto e representa não apenas a ditadura de Trujillo na República Dominicana, mas todos os processos autoritários latino-americanos.

Enquanto Carrillo ganha destaque na narrativa, o personagem Jesús, por sua condição própria de sequestrado escondido nos poróes da ditadura, aparece muito pouco no romance. Sabe-se o fundamental: que ele é enclausurado, que passa por condiçóes subumanas na prisão e finalmente é executado pessoalmente por Carrillo, que segue o conselho da primeira-dama sobre como eliminar o basco.

Notamos que fora do espaço dominicano, além de Enrique Lafourcade, outros escritores se interessaram em ficcionalizar a truculência do regime de Trujillo, principalmente na última década do século passado. O interesse pelo trujillato na literatura se sustenta pela projeção do tema proporcionada pelas obras destes autores estrangeiros, muitos deles consagrados internacionalmente. Cabe perceber que a partir do fenômeno midiático que inclui os romances, a mídia e o público leitor, ocorre um movimento de retorno ao passado em busca das origens deste tipo de narrativa. Desta maneira, uma obra recobra outra, que recupera outra e assim sucessivamente em um movimento espiral, partindo do mais atual para o passado. Institui-se um diálogo entre estas narrativas, formando uma cadeia dialógica que denuncia ao longo da história das literaturas hispânicas a tirania de Trujillo, símbolo de outros ditadores.

$\mathrm{Na}$ América, possivelmente o caso mais midiático de todos é de La fiesta del Chivo ${ }^{28}$ de Mario Vargas Llosa, seguido de En el tiempo de las mariposas de Julia Álvarez. Escritora de origem dominicana radicada nos Estados Unidos desde a infância, Álvarez publica primeiramente o romance em inglês In the time of the butterflies, sendo logo traduzido ao espanhol. A narrativa recupera a ditadura revelando a história de Patria, Minerva e María Teresa, as irmãs Mirabal, conhecidas como "as borboletas", atuantes opositoras ao regime tru-

28 Esta obra foi objeto de análise de nossa Dissertação de Mestrado intitulada La fiesta del Chivo de Mario Vargas Llosa: uma visão literaria da história, defendida em 2003 junto ao Programa de Pós-Graduação em Letras da UNESP, campus de Assis-SP. 
jillista. As irmãs Mirabal, ao assumir o compromisso político de atuar contra a ditadura, sofrem as conseqüências de seus atos. São, portanto, perseguidas: sofrem represálias do Serviço de Inteligência e, finalmente, são assassinadas brutalmente em 25 de novembro de 1960 em uma emboscada, poucos meses antes de Trujillo ser assassinado também. As irmãs Mirabal foram surpreendidas quando voltavam de Puerto Plata, onde também estavam encarcerados seus companheiros.

O que se coloca de diferente neste romance é que a narrativa se realiza a partir de uma voz feminina, a da narradora, que recupera outras vozes femininas, que sofreram de perto a tirania trujillista, lutando de acordo com suas possibilidades contra um regime caracteristicamente patriarca e opressor.

Das três Mirabal, Minerva é quem mais sente a presença do ditador, talvez porque seja também a mais comprometida de todas. A princípio, quando ainda era menina e estudava em um colégio interno de Santo Domingo, vê Trujillo como o verdadeiro pai da pátria, o benfeitor, que havia sido escolhido para salvar o seu povo. Entretanto, ao tomar consciência de que sua colega de turma Lina Lovatón iniciara um caso com o ditador, de maneira forçada, Minerva muda sua visão a respeito do tirano. O episódio de Lovatón é o início de sua conscientização política.

As histórias de estupros e das amantes de Trujillo são constantes na narrativa. No entanto, Minerva não aceita fazer parte de mais uma dessas histórias, por isso, quando já adulta, recusa as investidas do ditador em uma festa em sua homenagem. Como forma de se proteger, a personagem golpeia Trujillo na face, o que será motivo para todo tipo de perseguição, prisóes e espionagens dirigidas a ela e a todas as pessoas de suas relaçóes. A partir desse momento, a personagem passa a atuar mais fortemente no movimento de oposição designado 14 de Junio. Nesse espaço de resistência, as Mirabal são conhecidas como borboletas, o nome secreto de Minerva nas atividades clandestinas.

O romance de Vargas Llosa se assemelha bastante ao de Enrique Lafoucarde nos planos narrativos, embora não haja no romance de Vargas Llosa um foco narrativo exclusivo para narrar o desaparecimento de Galíndez. No caso de La fiesta del chivo, os focos narrativos explicitam as vozes da personagem Urania Cabral, de Trujillo e do grupo de conjurados; entretanto, a história de Galíndez, bem como a das irmãs Mirabal, também são narradas. 
Em La fiesta del Chivo podemos constatar três planos narrativos principais, que caminham separadamente, mas que, ao final, conjugam-se em um todo narrativo. Estes pontos de vista diferentes proporcionam ao leitor uma visão da República Dominicana a partir de diferentes perspectivas, levando o leitor a uma visão mais complexa e abrangente dos dados históricos recriados.

$\mathrm{O}$ recurso que o narrador utiliza para entrelaçar tais focos de narração são os saltos temporais, designados "caixinhas chinesas" pelo crítico José Luis Martín ${ }^{29}$, ao examinar os processos narrativos presentes em algumas obras de Vargas Llosa desde o início de sua carreira de romancista. Sendo assim, cada uma das focalizações se desenrola em um tempo diferente, porém, estão intimamente relacionadas à composiçáo da trama da narrativa.

No caso de Urania, a narrativa parte de 1996 para voltar ao passado da personagem e atualizar a época da ditadura de Trujillo. O retorno à infância e à adolescência ocorre por meio do discurso da memória, em que se alternam o presente e o passado através de constantes flashbacks. A protagonista recorda porque está novamente na República Dominicana, depois de trinta e cinco anos de ausência e sem nenhum contato com a família.

Já a temporalidade de Trujillo é outra, pois a narrativa do ditador se concentra no último dia de sua vida. O Generalíssimo levanta-se às cinco horas da manhã e não tem consciência de que este é o dia de seu assassinato. Assim, a narrativa, no início, focaliza 1996, para retroceder, em seguida, a 1961, ano da morte do ditador. Entretanto, assim como ocorre com Urania, Trujillo, ainda que estando em 1961, rememora seu passado glorioso de trinta e um anos da Era. Com efeito, as lembranças de Trujillo remetem-nos aos seus primeiros anos como governante da República Dominicana, bem como nos revelam sua ação de gerir o país por meio da violência e da crueldade. Ressalte-se que o tirano apresentado pelo narrador já é o homem decadente, que vai perdendo, paulatinamente, a capacidade de governar.

A temporalidade do grupo de opositores de Trujillo concentra-se na noite do assassinato do ditador, uma terça-feira, dia 30 de maio de 1961. O grupo está à espera do tirano, que deve passar pela estrada em que estão aguardando para a realização da emboscada. Esta espera deflagra a memória de cada perso-

29 MARTÍN, José Luis. La narrativa de Vargas Llosa: acercamiento estilístico. Madrid: Gredos, 1974. 
nagem, revelando ao leitor os motivos que impelem suas açóes.

Para finalizar, observa-se que a partir da publicação do romance de Vargas Llosa ocorre um impulso para a produção de novas formas de representação do tema, como é o caso da transposição para o cinema dos romances En el tiempo de las mariposas de Julia Álvarez e do próprio La fiesta del Chivo ${ }^{30}$, além de um redescobrimento dos romances publicados anteriormente sobre a mesma temática.

É importante ressaltar que atualmente o fenômeno da literatura do trujillato continua; a exemplo, temos o caso do romance The brief wondrows life of Oscar Wao (traduzido para o espanhol com o título La maravillosa vida breve de Óscar Wao) do escritor dominicano Junot Díaz, publicado em 2007, nos Estados Unidos.

\section{FICCIÓN E HISTORIA EM LA REPÚBLICA DOMINICANA: TENSIONES DE LA DICTADURA TRUJILLISTA EM LA LITERATURA CONTEMPORÁNEA}

\section{RESUMEN}

El artículo analiza brevemente cuatro obras consideradas fundamentales para la comprensión de la novela del trujillato en Hispanoamérica, fenómeno literario que surge a partir de la ocurrencia histórica de la dictadura de Rafael Leónidas Trujillo en la República Dominicana. Estas narrativas tienen como punto central la ficcionalización del periodo histórico a debate, y revela los problemas impuestos por la dictadura trujillista.

PALABRAS CLAVE: Literatura, Historia, Literatura Hispanoamericana, novela del trujillato.

Recebido em: 17/03/12

Aprovado em: 16/11/12

30 O primeiro filme rodado foi En el tiempo de las mariposas 2001, seguido por La fiesta del chivo em 2005. 